\title{
perifèria
}

Número 13, diciembre 2010

www.periferia.name

\section{Reconstruyendo los hitos de la antropología. Con Teresa del Valle}

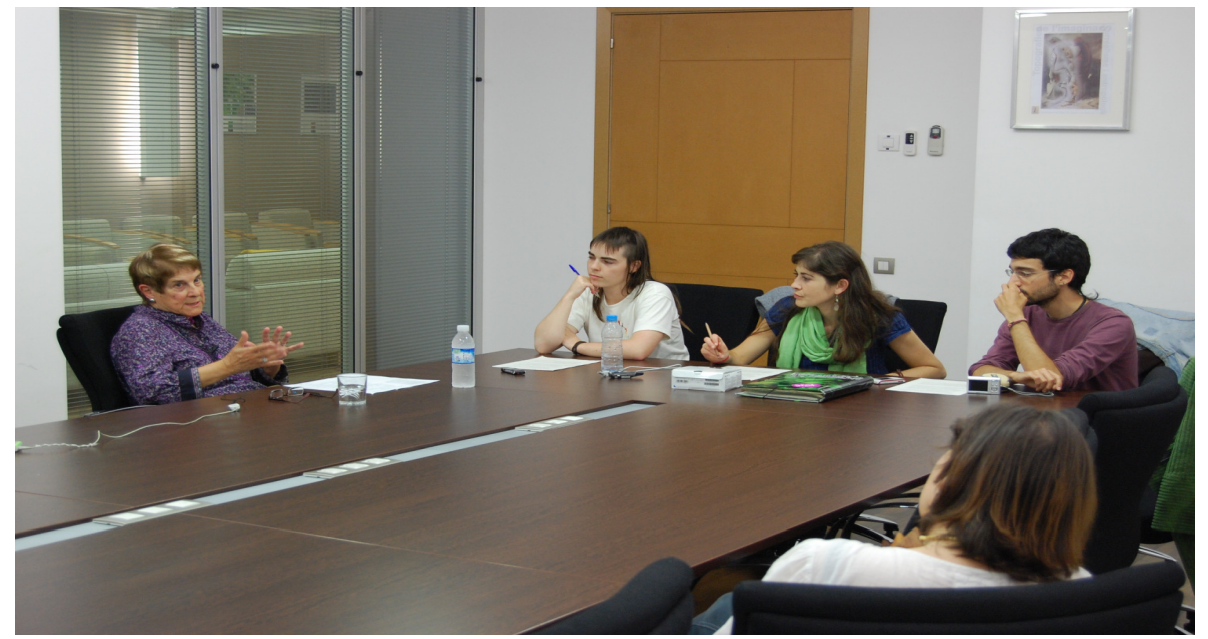

(Fotografía: Xavi Zulet)

"La Antropología tiene un campo muy importante en el análisis de las fisuras, en detectar las fisuras, estudiarlas y manifestarlas."

Autoras: Blanco, Quesé; Egido, Sara; Aubinyà, Axel - Universitat Autònoma de Barcelona $^{1}$

Directora: Montserrat Clua Fainé

\footnotetext{
${ }^{1}$ Enviar correspondencia a: Montserrat Clua, Montserrat.clua@uab.cat
} 


\section{perifèria}

Número 13, diciembre 2010

www.periferia.name

\section{Resum}

En aquesta ocasió el Projecte Entrevistes ofereix una entrevista a la historiadora i antropòloga Teresa del Valle Murga, catedràtica de la Universitat del País Basc. L'entrevista es féu el 12 de maig a Barcelona, aprofitant la visita de Del Valle a Catalunya per participar en el simposi internacional "Procreació, criança i gènere. Aproximacions antropològiques a la parentalitat" que es va celebrar a la UAB. Navegant per un mar de preguntes, l'entrevista reflecteix la trajectòria i pensament, des de i per a l'antropologia, d'una personalitat fonamental en el desenvolupament de la disciplina a Espanya i al País Basc. Alhora que ens ofereix la seva visió de l'evolució interna de l'antropologia espanyola. Una entrevista que combina, doncs, els elements més biogràfics amb els temes que més han interessat a una pionera i principal referent en antropologia del gènere al nostre país, fent una especial menció al seu últim treball sobre la memòria.

\section{Resumen}

El Proyecto Entrevistas ofrece esta vez una entrevista a la historiadora y antropóloga Teresa del Valle Murga, catedrática de la Universidad del País Vasco. La entrevista tuvo lugar el 12 de mayo de 2010 en Barcelona, coincidiendo con la participación de Del Valle en el simposio internacional «Procreación, crianza y género. Aproximaciones antropológicas a la parentalidad» que se celebró en la UAB. Navegando por un mar de preguntas, la entrevista refleja la trayectoria y pensamiento, desde y para la Antropología, de una personalidad fundamental en el desarrollo de la disciplina en España y en el País Vasco, al mismo tiempo que nos ofrece su visión de la evolución interna de la antropología española. Una entrevista que combina los elementos más biográficos con los temas que más han interesado a una pionera y principal referente en antropología del género en nuestro país, con una especial mención a su último trabajo sobre la memoria.

P: Para comenzar la entrevista queríamos preguntarte por tus inicios en la Antropología, que justamente tuvieron lugar fuera de España. ¿Qué circunstancias confluyeron para que una mujer de 24 años, en plena época franquista, marchara a formarse a Estados Unidos y seguidamente a Hawai?

Teresa del Valle: Que mayor es una ¿no?, cuando se lo recuerdan... [risas]. Es como retrotraerme a toda una historia. Pues verdaderamente fue una circunstancia que no tenía nada que ver, en principio, con lo académico; sino un tipo de opción 


\section{perifèria}

Número 13, diciembre 2010

www.periferia.name

de vida que en aquel momento hice, que fue entrar en una congregación internacional de misioneras que fue fundada en el País Vasco y contaba con una larga trayectoria de trabajo educativo muy consolidada. Yo había sido colegiala (también mi hermana Begoña) en el colegio de la Vera Cruz. Primero de Bilbao y luego en Berriz -que era un internado en un pueblecito pequeño de Bizkaia-. Y yo siempre suelo decir esto: que sabía más del Extremo Oriente y de Oceanía que de los viajes de Cristóbal Colón. Porque al ser una congregación misionera que tenía casas y colegios en Japón, en China, en las Islas Marianas, en las Islas Carolinas, en México y en algunos otros sitios, pues esa relación con lo que podían ser lugares lejanos entonces -que ahora ya no lo son tanto-, con culturas, con lenguas, con formas de comportamiento diferentes, estaban ya en mi primera educación. Recuerdo que siendo colegiada en esos momentos (primero en el colegio de la Vera Cruz de Bilbao) solían leernos cartas de las misioneras y de los misioneros relatando costumbres, rituales,... Siempre también bajo un prisma de lo que se consideraba pagano y no pagano, ¿no? Entonces ese tipo de ideología estaba presente, porque era la ideología dominante desde las congregaciones de misioneros y misioneras, la gente que iba a trabajar allí. Y también había una relación muy estrecha con la religión.

Cuando yo tenía 21 años decidí entrar en esa congregación porque quería trabajar en Micronesia, en Oceanía. Cuando entré, en aquellos momentos Micronesia, donde trabajaban las Mercedarias Misioneras de Berriz, estaba bajo el mandato de los Estados Unidos, que se lo había otorgado las Naciones Unidas después de la Segunda Guerra Mundial. Por lo tanto, un requisito importante era el dominio del inglés, y también tener titulaciones norteamericanas. Entonces a mí me mandaron a estudiar a los Estados Unidos. Por eso yo digo que toda mi formación es una formación americana y estaba orientada a que luego iba a ir a trabajar a Micronesia. En respuesta a la pregunta, esa era la razón porque a los 24 años me fui a los Estados Unidos. Porque verdaderamente en la época franquista que una persona fuera a Estados Unidos, a no ser que provinieras de una familia de un alto nivel económico que te mandara a estudiar fuera, esto no era lo habitual, ¿verdad? 


\section{perifèria}

Número 13, diciembre 2010

www.periferia.name

En Estados Unidos recibí una formación americana, pues estudié primero en el College y lo hice en especialidades de Historia de Estados Unidos y de Arte. Luego ya me enviaron -porque digamos esto era un mandato- a Saint Louis, a la universidad de los jesuitas, una universidad privada, y allí estudié Historia de América Latina ${ }^{2}$. Hice mi tesina $-\mathrm{y}$ eso es curioso -, precisamente sobre la colonización española en las Islas Marianas, que fue una colonización que duró desde el 1521 y acabó en 1898. Hice la tesina desde un punto de vista crítico de la colonización española a comienzos del diecinueve, hasta los finales de la colonización. Más tarde fui ya como profesora a la universidad pública de Guam (que es la capital de las Islas Marianas) y allí estuve como profesora en el departamento de Historia, impartiendo clases principalmente de Historia de los Estados Unidos y trabajando como investigadora en el Micronesian Area Research Center de la misma universidad. Esta experiencia fue importante porque en ese sistema (que es un sistema bastante abierto, igual más si lo comparamos con nuestro sistema, que es más cerrado) tuve la oportunidad de diseñar un curso sobre Historia de Micronesia que se admitió en el currículum. Había un investigador jesuita (Fran Hezel) que era muy buen historiador (y también yo diría antropólogo), que había trabajado en esa dirección. Entonces a partir de lo que él había hecho y lo que yo había ido recogiendo, diseñé un curso de Historia de Micronesia. La característica principal era que, a diferencia de lo que había sido otro curso que se había dado sobre la Historia de Guam, yo me basaba principalmente en fuentes orales y también en la investigación que yo había estado haciendo. Fue un comienzo también de antropología. Recogía e incorporaba también los conocimientos locales del alumnado.

Pero la base de cómo yo me empecé a enganchar con la antropología fue cuando estaba en Saint Mary's College haciendo lo que sería el equivalente al grado nuestro ahora. Tuve un profesor que había estado en los Cuerpos de Paz, lo que se llamaba "Peace Corps", que era el sistema que se creó a partir de Kennedy. Tenía

\footnotetext{
2 Teresa del Valle es «Bachellor of Arts» (St. Mary College, 1966); «Master of Arts» (Antropología) por la Universidad de Hawaii, 1974; Diplomada en métodos de Análisis cultural (East-West Center, Honolulu, Hawaii, 1978) y Doctora en Antropología (U. de Hawaii, 1978).
} 


\section{perifèria}

Número 13, diciembre 2010

www.periferia.name

su orientación colonialista evidentemente, pero el proyecto enganchó a la juventud americana que iba, cuando acababan el College, a trabajar en distintos lugares. En concreto, Micronesia era uno de los sitios. Y esos estudiantes entraban en lo que serían las comunidades, trabajaban desde dentro, y siempre además aprendiendo las costumbres y la lengua.

Cuando estaba haciendo el grado, tuve la oportunidad de tomar un curso mixto que era de Sociología y también de Antropología, con un profesor que había estado de Peace Corp en India. La vivencia de cómo él comunicaba lo que había sido su experiencia y luego la introducción que nos fue haciendo de las culturas... fue muy importante. Por ello sitúo ahí mi introducción a la antropología. Y figuraos que no había reflexionado yo mucho sobre esto. Y de ahí lo que muchas veces decimos de que las preguntas generan conocimiento..., pues he estado pensando que sí, el enganche primero lo sitúo en esa experiencia académica.

También es verdad que yo tenía una base en antropología, porque como os digo, en la Congregación de las Mercedarias Misioneras había, diríamos, una práctica importante de que cuando se iba a un sitio distinto a trabajar, había que conocer la cultura y de ahí esa apreciación. Además, que en esa congregación, cuando yo estuve en Estados Unidos, estábamos gente como de once países distintos: de Japón, de China, de México, de otros sitios de América Latina, de Norte América evidentemente... Y quieras o no, aunque el inglés era el lenguaje común, había un compartir experiencias, vivencias, y también conocimientos de las distintas culturas. Entonces esos tres elementos entrarían en esa base de mi enganche por la antropología.

\section{P: Dado que su trabajo de campo fue en las Islas Marianas sobre la colonización española, ¿cree que sigue existiendo influencia del colonialismo en la antropología contemporánea?}

Teresa del Valle: A ver, es que no fue exactamente sobre el colonialismo mi tesis; la tesis fue sobre parentesco, estrategias de matrimonio, para comprender el cambio cultural fijándome principalmente en el parentesco y el matrimonio, y el sistema de tenencia y uso de la tierra por la importancia que tenía. Entonces, sí que 


\section{perifèria}

Número 13, diciembre 2010

www.periferia.name

entró la colonización en el contenido de mi tesis, pero de otra manera, no como objeto central de estudio. Sí que mi tesina había sido sobre la colonización propiamente dicha, pero en la tesis mi foco de interés eran las estrategias de parentesco.

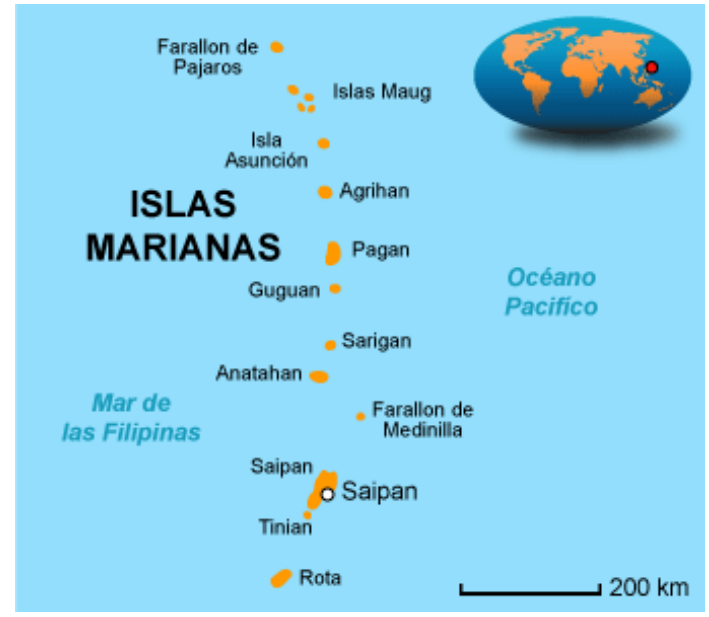

Hice mi trabajo de campo en el sur de la isla de Guam, en un pueblecito de 752 habitantes, en aquellos momentos que se llamaba Umatac, que era el lugar donde había desembarcado Magallanes, cuando en su viaje alrededor del mundo llegó a Las Marianas. De modo que allí fue mi primer encuentro con los colonizadores y los nativos del lugar, los chamorros. Ahí sí que tuve que contextualizar la situación porque evidentemente la cultura chamorra tuvo una evolución fortísima, resultado de los encuentros entre los navegantes, los colonizadores, los misioneros que fueron, y lo que era la gente autóctona de la isla. Pero eso fue en 1521. Entonces lo que fui observando es como la cultura va cambiando, cogiendo como punto de partida para un análisis comparado lo que eran comienzos del siglo XIX, los años veinte, porque era cuando principalmente cristalizó lo que luego se ha llamado cultura chamorra, que es una cultura con un mestizaje profundo.

A lo que me has dicho que mi estudio fue sobre los patrones de colonización, la verdad es que no ha sido un estudio que haya seguido haciendo, sino que el foco de interés en mi tesis considero que fue más encaminado a la obtención de 


\section{perifèria}

Número 13, diciembre 2010

www.periferia.name

conocimiento respecto a la sociedad chamorra. Lo que era el mestizaje, la transformación tan profunda de las estructuras familiares, de las estructuras de tenencia de la tierra... Eso fue lo que a mí me parecía en realidad importante, porque en el contexto del departamento de la Universidad de Hawai donde estuve haciendo mi máster de antropología y luego el doctorado, la tierra era un elemento de estudio muy importante en las sociedades insulares, donde la tierra tiene tal importancia por su escasez y también por la relación tan estrecha con las estructuras de parentesco y las alianzas matrimoniales. En ese sentido, sí que hablo del impacto que tuvo la colonización, pero también de cómo la gente supo ir buscando sus estrategias en el reparto y uso de la tierra. En aquellos tiempos el gobierno español había centralizado lo que era el poder sobre la tierra, pero luego las estrategias se habían ido desarrollando en relación a las alianzas de parentesco, y también en relación al poder simbólico. Hablo del cómo a través de mecanismos que tenían que ver con el impacto de otros poderes que estaban por encima del control del ser humano, la propiedad mostraba continuidades a nivel simbólico. No tanto en relación con deidades, sino más bien con creencias en el poder de Taotamona, basado en la existencia de unos personajes que según las creencias, habían permanecido en los bosques, controlando ciertas tierras, y cuya presencia se remontaba a cuando los españoles habían desembarcado en 1521 . Por ello estuve viendo los distintos tipos de estrategias, las referencias a la presencia de los Taotamona, junto con las estrategias matrimoniales y otro tipo de estrategias relacionadas con resistencias ante el colonialismo.

Me has preguntado sobre el colonialismo en general, tema del que puedo tener mis ideas pero del cual no me considero una experta como para hablar de ello.

\section{P: En su regreso a España en la década de los 80, ¿cómo encontró la situación de la antropología española?}

Teresa del Valle: La verdad que fue un encuentro en distintos momentos. Por ejemplo, cuando volví fue un momento en que me desvinculo de la Congregación de las Mercedarias Misioneras. Llegué a Euskadi, en concreto a Bilbao, con mi doctorado flamante, con unas ganas de trabajar impresionantes, y todavía 


\section{perifèria}

Número 13, diciembre 2010

www.periferia.name

pensando que volvería a Estados Unidos, pues yo tenía allí mi puesto de trabajo, precisamente en la Universidad de Guam, que es donde se esperaba que volviera. $Y$ es entonces cuando me encuentro que itengo que empezar a convalidar absolutamente todo lo que durante esos años había logrado en cuanto a estudios superiores...! [Tono de exaltación y sorpresa]. Ese es el motivo por el que yo acabo con tantos títulos y tantas licenciaturas. Camino, por otro lado, que los que aquí estáis ya habéis encontrado totalmente llano.

Lo primero que me encontré fue que en la Universidad del País Vasco no se realizaba ni un curso de Antropología Cultural. José Miguel de Barandiaran sí que había tenido una cátedra de Antropología, que no sé cómo se denominaba. Sólo sabía que la hizo en la Universidad del Opus de Navarra, en Pamplona. También había un instituto con una tradición vinculada a la diócesis de Bilbao en el que trabajaban lo que era la etnografía desde las enseñanzas de Barandiaran. Es decir, que utilizaban la etnografía en el sentido de describir, de recoger los datos siempre de la forma más fidedigna, y también a poder ser, vinculada a las personas autóctonas del mismo sitio. Por ejemplo, si se hacía un estudio sobre un pueblo de Zianuri, en Vizcaya, pues a poder ser, se primaba que lo hiciera gente de Zianuri.

Entonces había un gran énfasis en lo que era la recogida de datos de la forma más fidedigna, a partir de seguir un cuestionario que Barandiaran había establecido y que estaba orientado a crear un atlas etnográfico del País Vasco. Yo estaba en contacto con algunas personas de ese instituto, el Instituto de Labayru, que todavía existe. En él había personas que se habían formado en Francia, concretamente en París, y otra gente que se había formado con Barandiaran. De modo que, aunque en la Universidad del País Vasco no había ningún hueco para mí, tuve una buena recepción por parte del Dr. Basabe, quien estaba especializado en Antropología Física. Aún estando yo (según el sistema tradicional norteamericano) especializada en Antropología Social, recuerdo que en los EUA teníamos que coger a nivel de máster y luego del doctorado, seminarios en las cuatro áreas tradicionales: en Arqueología, Arqueología Lingüística, Antropología Biológica, y Antropología Social; y luego ya te especializabas. 


\section{perifèria}

Número 13, diciembre 2010

www.periferia.name

Bueno, pues gracias a eso, a su buena acogida, y a que me permitiera asistir a sus clases como invitada sí que tuve, no un hueco en la enseñanza, pero sí que me permitió por lo menos estar dentro del marco universitario, lo que como si dijéramos era como respirar. Y me invitó a dar algunas sesiones sobre antropología social y ecología dentro de uno de sus cursos

Poco después se creó un movimiento de gente interesante que montó una serie de talleres en la Universidad, pero no dentro de la estructura oficial, sino que estaban vinculadas más como áreas de extensión universitaria. Fue entonces cuando yo monté un taller de Antropología en el que hubo mucha gente interesada en participar. Sobretodo gente que venía de otras disciplinas, como eran Biológicas, o la carrera de Arte, o de Sociología.

Por otro lado tuve también una buena acogida por parte de Alfonso Pérez Agote, sociólogo, que aunque se encontraba en la Facultad de Económicas, estaba inmerso en el campo de la Sociología. En aquellos momentos estaba muy interesado en el tema de la etnicidad, concretamente en la obra de Barth y coincidió que yo venía con todo eso muy fresco debido a mi formación americana y puede encontrar en Pérez Agote un interlocutor.

Su apoyo fue también clave y muy importante de cara a mi entrada en la Universidad del País Vasco. Entonces, para que veáis el panorama, también fue muy interesante el hecho que el Dr. Basabe, un día me dijera: "Pues Teresa, igual te interesa, porque va a haber una asamblea en un lugar del País Vasco, en Oñate, y se va a tratar de revitalizar Eusko Ikaskuntza" (la Sociedad de Estudios Vascos, que era una sociedad que se había fundado ahora hará ya 93 años, en 1918, y que había tenido como objetivo el estudio de la cultura vasca). La etnografía había sido una sección muy importante en Eusko Ikaskuntza, y Barandiaran, que era quien de alguna forma había desarrollado todo aquello, había estado en silencio por cuestiones de política. Por lo que la Sociedad de Estudios Vascos cesó en su actividad al tener que irse Barandiaran al exilio a Sara, un pueblecito en Iparralde, en la parte francesa de Euskadi, para no volver hasta mediados de los años sesenta. 


\section{perifèria}

Número 13, diciembre 2010

$\underline{\text { www.periferia.name }}$
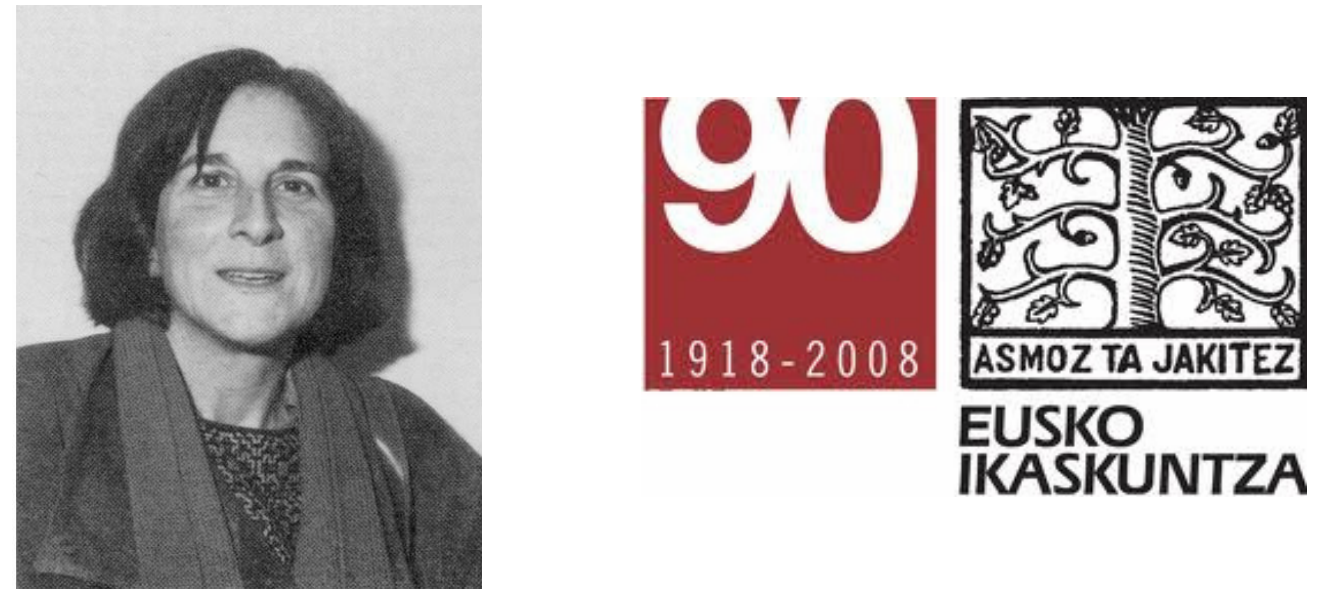

De modo que acudí con Basabe a esa asamblea en Oñate y entonces vi que ese era el lugar en que yo quería estar. Ya para entonces había vuelto a Estados Unidos para ver si realmente quería quedarme en Estados Unidos o quedarme aquí, resultando finalmente la opción de quedarme aquí y entrar como socia a formar parte de la Sociedad de Estudios Vascos. Ese fue un momento importante porque supuso encontrarme con la gente que durante todo el tiempo que yo había estado en Estados Unidos y en Micronesia, había estado no solamente peleando en contra del franquismo, sino avanzando en el estudio de lo que era el estudio de la cultura vasca. Pero al mismo tiempo para mí era muy duro, porque yo venía de un sistema en que la Antropología académica tenía ya una trayectoria que nadie la cuestionaba, que estaba muy reconocida... Y era, de repente, encontrarme con otra tradición que era más de la Escuela Histórica de Viena, que aún estando también muy relacionada con la Arqueología, se trataba de un tipo de Arqueología que no era la Arqueología más sistémica en la que yo me había formado a partir de algunos seminarios... Por lo que me resultó muy duro. Luego vino Jesús Azcona, quien había estudiado Antropología en Alemania y también entró en la sección de etnografía de Eusko Ikaskuntza. Y ahí, bueno, intentamos al menos manifestar las otras tradiciones de dónde veníamos y según nuestra formación, ¿no? Lo que no resultaba nada fácil. Pero bueno, yo estuve allí. $Y$ ahora es curioso porque ahora estoy en Eusko Ikaskuntza como vicepresidenta electa por Guipúzcoa en mi 


\section{perifèria}

Número 13, diciembre 2010

www.periferia.name

segundo mandato, ya con una situación muy, muy distinta.

Al hilo de esto quiero recalcar también cual es mi relación con Barcelona, cómo yo entro en Barcelona. El caso es que voy a Barcelona para conocer a Claudi Esteva, motivada por el hecho de que el primer decano de la recién creada Facultad de Filosofía de Donosti era Ramón Valls, quien era catalán. Resultó que ya en el segundo año de estar en Euskadi, me entero precisamente por parte de Pérez Agote, de que la Facultad de Filosofía se había fundado el año anterior en Donostia y que ese segundo año es cuando se iba a introducir la Antropología Social. Y claro, Alfonso Pérez Agote era sociólogo, pero muy cercano a la Antropología, y conocía el valor de la Antropología. Entonces, bueno, lo que son las redes ¿no? Porque yo, a Alfonso Pérez Agote, le conocí a través de personas muy cercanas a mí, como por ejemplo mi hermana, quien era pintora y estaba muy metida en los círculos no solamente del arte, sino conectada con otros círculos de distintos intereses artísticos y de gente que estaba en la Universidad. Entonces me dijo esto y nos fuimos en coche los dos para entrevistarme con Valls, a quien le gustó la trayectoria que yo había seguido, y también, más tarde al rector de la Universidad, que era un hombre muy abierto. Así fue como entré en la Universidad. Que entonces entrabas, no tanto a través de concursos muy elaborados como ahora, sino que en una Universidad todavía muy joven, era más bien ir fichando a gente. En esos momentos nuestra facultad estaba en el segundo año, que era cuando empezaba la antropología, y así entré.

Yo siempre digo que se desarrolló la antropología social como se podía haber desarrollado la antropología filosófica, porque yo entré en Filosofía. Los filósofos querían hacer antropología filosófica, y yo, desde luego, entré como antropóloga social. Y así fue. Muchas veces las trayectorias son más producto del contexto que de otras planificaciones súper importantes.

Volviendo al tema de Barcelona... Un problema que tenía era que yo tenía que convalidarlo todo, porque a efectos de aquí, esto era como si hubiese estado en no sé donde, pero no tenía ningún reconocimiento. Y entonces tuve la gran acogida de Claudi Esteva. Desde luego yo le tengo tal afecto a Claudi porque se portó conmigo 


\section{perifèria}

Número 13, diciembre 2010

www.periferia.name

de una manera magnífica; y también a María Jesús Buxó. Entonces yo vine a través de Valls que Ilamó a Claudi y yo aparecí. Solía viajar de noche en tren-litera (tampoco tenía mucho dinero) y venía aquí; y a veces volvía al día siguiente o a los dos días. Me solía quedar siempre en casa de María Jesús Buxó. Había veces que viajaba con otro colega también de filosofía; venía también a Barcelona por las mismas razones, porque él había estudiado en Francia.

Entonces, ¿qué pasó? Que tuve que convalidar mi licenciatura y se convalidó con Geografía e Historia. Me fueron convalidando y algunas asignaturas las tuve que hacer. Luego mi tesina la traduje y defendí la tesina sobre las Islas Marianas. Fue muy curioso porque a veces tenía que estudiarme toda una materia en muy poco tiempo. Un profesor de geografía (no recuerdo en estos momentos su nombre, pero que era toda una eminencia), me decía: "Teresa, tú de antropología mucho, pero de geografía..., algunas cosas..." Y yo decía:"iDe acuerdo!".

Y luego defendí la tesina. Entonces acabé con título de la Universidad de Barcelona. Y luego la tesis también la tuve que convalidar; me la convalidaron por la Universidad del País Vasco, en la Facultad de Geografía e Historia, de donde también tengo un doctorado. Luego tengo mis dos másteres en Antropología y en Historia por distintas Universidades americanas, y luego el doctorado en antropología social por la Universidad de Hawai. Así que creo que soy uno de los ejemplos de una época en la que podías estar haciendo los estudios en Francia, en Alemania o en Estados Unidos, pero venías aquí y no había ningún reconocimiento, porque los trámites a través del Ministerio eran tan largos... La Universidad del País Vasco me exigía (ya estaba contratada) que tuviera el reconocimiento cuanto antes. Por eso la Universidad de Barcelona para mí fue excelente, porque supieron ver lo que pasaba con el sistema, y me dieron las facilidades que se podían dar de hacerlo de esa manera.

\section{P: Toda una aventura....}

Teresa del Valle: Pues sí, toda una aventura. Porque también la historia de la disciplina es, como sabéis, una historia de lo estructural, del mundo académico. Pero también de las personas, porque a través de las personas también vas viendo 


\section{perifèria}

Número 13, diciembre 2010

www.periferia.name

los contextos, ¿no?

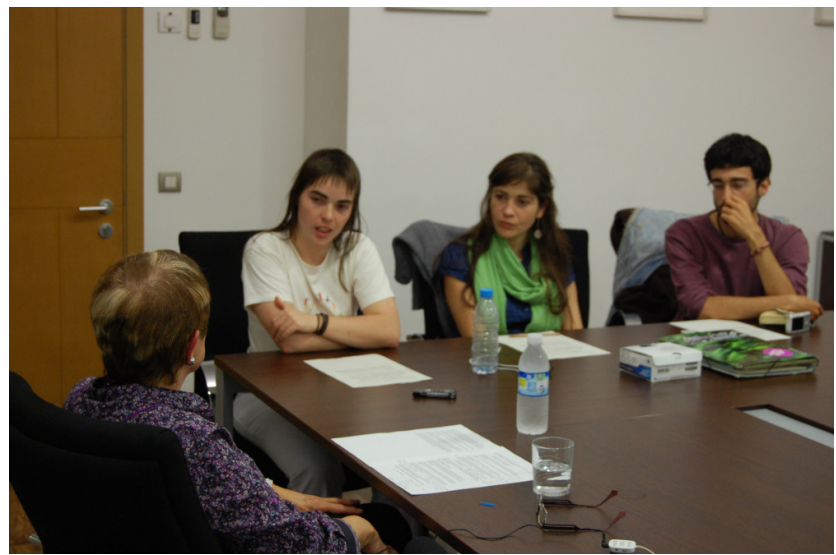

«La Historia de la disciplina es una Historia de lo estructural, del mundo académico. Pero

también de las personas,

porque a través de las

personas también vas viendo

los contextos.»

(Fotografía: Xavi Zulet)

P: Siguiendo en el ámbito universitario desde una visión general, y más concretamente desde la antropología social, partiendo también de su experiencia como miembro en la comisión estatal para la elaboración del plan de estudios para la licenciatura: ¿cómo ve el panorama actual y futuro de la universidad teniendo en cuenta los estudios que ha realizado sobre la Universidad Pública?

Teresa del Valle: Primero decir que yo valoro muchísimo la enseñanza pública, estoy totalmente a favor de una enseñanza pública excelente. Yo creo que es lo que tenemos que hacer.

Comienzo por lo del grado. Ha sido muy interesante para mí y yo creo que para mis colegas que participamos en el período anterior de la implantación de la licenciatura. Creo que ha sido importante ver las redes que se han creado; es decir, ha sido un buen ejemplo de cómo gente universitaria en determinados momentos puede asumir el compromiso político de introducir una disciplina al nivel que le corresponde -que en este caso era el de grado. Por lo que he seguido había gente de la Autónoma, Complutense, de la Universidad de Granada, lo mismo que de la Universidad del País Vasco, Sevilla, Autónoma de Madrid, Alicante... Cuando voy a un sitio comentamos con la gente acerca de cómo están implantando los estudios 


\section{perifèria}

Número 13, diciembre 2010

www.periferia.name

de grado. Y casi siempre hay una valoración de cómo se ha creado un tejido de compromiso en el que se ha trabajado de manera unánime. $Y$ de cómo ha beneficiado no solamente a todo el colectivo, sino también a la Universidad específicamente. Por lo que voy viendo hay ya documentos que han ido circulando. Y luego se sabe que en tal Universidad ya se ha empezado el grado. Cuando acaben el primer año vamos a tener esa experiencia. Yo creo que eso ha sido muy interesante.

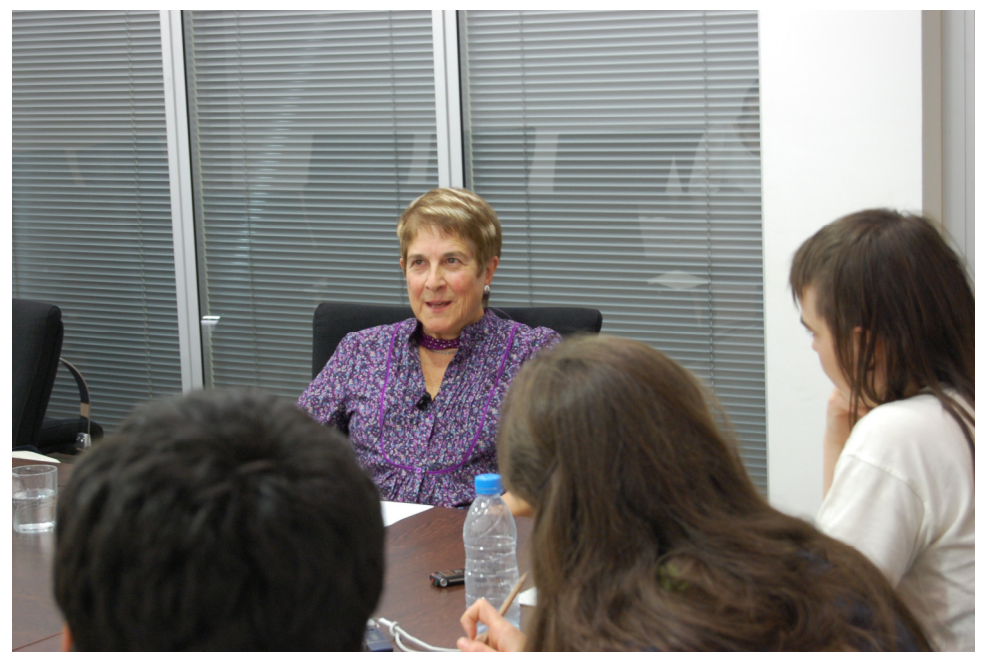

$\ll A$ vosotros os toca la profesionalización.»

«Hay también toda una serie de mecanismos que se están poniendo en marcha de "formas distintas de hacer".»

(Fotografía: Xavi Zulet)

Y también creo que también ha sido un buen ejemplo de cómo las cosas no suceden todas al mismo tiempo, evidentemente. Hay compromisos que tienen que ver con distintas generaciones. Es decir, que a la generación de Claudi Esteva, y luego de Lisón Tolosana, les correspondió traer la antropología; Claudi Esteva desde México y Lisón Tolosana desde Inglaterra. Ellos fueron introduciendo, junto con otra gente que también estaba en las universidades, lo que eran las distintas disciplinas: Lisón Tolosana en Sociología, Claudi Esteva en Historia. Luego otra gente fue viniendo y trabajando en ese sentido. Entonces llega el periodo en que nos toca a otras generaciones. Y que también se aportan experiencias que se tienen (como ya en esa primera parte, la de Esteva y la de Lisón Tolosana), de otras experiencias universitarias. $Y$ ahora le toca a la generación que ya se ha formado, 


\section{perifèria}

Número 13, diciembre 2010

www.periferia.name

que ya ha tenido esas referencias de lo anterior, que ha podido ver cómo ha funcionado la licenciatura. Es otro tipo de visión, una visión más de futuro porque ya se está viendo, lo siguiente después de la licenciatura, del grado. ¿Qué es lo que va a ser? Pues ya es completar: va a tocar lo de la profesionalización. A vosotros os va a tocar la profesionalización, y sobre todo, el entrar en los sistemas políticos, económicos, de la administración, de la investigación,... Fuera del mundo académico. Bueno, gente estaréis en el mundo académico, pero la mayor parte os tocará trabajar en otros sitios.

Creo que el momento actual es un momento que sí tiene futuro. $\mathrm{Y}$ es un momento de recopilación; para mí, de evaluación, de sensibilización a las necesidades de hoy. Y también de conciencia, de cómo introducir en lo que sería el mundo laboral en toda su diversidad, una disciplina que es difícil de encajar, porque es una disciplina creativa. Es precisamente una disciplina que va a estar siempre en tensión, porque si no estuviera en tensión perdería lo que está centrado en la antropología, que es la capacidad de reflexión desde las realidades cambiantes. Y también de como esas realidades cambiantes se deben analizar teniendo en cuenta derechos humanos, diversidad cultural, sistemas antagónicos, sistemas de opresión y desigualdad, sistemas colonialistas, sistemas en los que los derechos humanos no están contemplados... Es una disciplina con una gran potencialidad de análisis, de interpretación y de posibilidades de generar riqueza. Riqueza en el sentido de conocimiento pero también de poder estar en los sitios, en las asesorías, en las consultoras, en la administración, en la docencia, en el urbanismo, en equipos multidisciplinares, en las entidades locales y en entidades estatales, y en entidades internacionales. Pero el sentido crítico que en unos tiempos tuvo que ver con la colonización: cantidad de antropólogos en un momento dado se vieron en tensiones impresionantes de cómo navegar en procesos colonialistas (con los que luego también hemos sido muy críticos). Pero luego también en otros momentos ha tocado criticar al multiculturalismo, perdón, al relativismo visto desde el multiculturalismo, visto desde los derechos humanos. También crítica, pues, a lo que pueden ser procesos de olvido de derechos, de historias que han ocurrido, o crítica a lo que es, por ejemplo, sistemas salvajes de desigualdad de género, 


\section{perifèria}

Número 13, diciembre 2010

$\underline{\text { www.periferia.name }}$

generadores de violencia en cuanto a las mujeres, de sistemas producto de la represión histórica, y la represión de grupos,... Lo que quiero decir es que es una disciplina que tiene unas fuentes de tensión importantes, yo que trabajo la tensión, no la veo desde el punto de vista negativo. La tensión como fuerzas contrapuestas puede ser tensión negativa, pero puede ser también tensión crítica, creativa, tensión positiva.

\section{P: Ahora queríamos entrar un poco más en preguntas vinculadas con su trabajo, con los temas que ha desarrollado. En primer lugar, dentro de la antropología de género y como antropóloga feminista: ¿cómo cree que ha evolucionado el androcentrismo en Occidente?}

Teresa del Valle: Bueno, esa pregunta creo que es objeto de varias tesis doctorales....

\section{P: Sí, pero algo breve,.... [risas]}

Teresa del Valle: Creo que ha sido muy importante la sistematización y la presencia de los estudios feministas y de género en la Universidad, porque son los que están permitiendo en estos momentos que podamos hacer los análisis desde la crítica al androcentrismo. En este momento podemos decir que contamos ya con categorías, con teorías, con metodologías, con estudios excelentes que se han llevado a cabo en los distintos campos, tanto en la economía como en la historia, en la filosofía, en la literatura, en la antropología,... Evidentemente, porque la crítica feminista es multidisciplinar por naturaleza, y también se nutre a su vez de un movimiento social que es el movimiento feminista. El movimiento feminista, a su vez, aúna teoría y aúna práctica, y aúna una práctica cognitiva. Creo que, en su conjunto, este campo nuevo del saber -podemos decir que se remonta (según algunas corrientes a las que yo me adscribo) a La Ilustración; también al movimiento sufragista, al movimiento feminista, y referente a la sistematización e incorporación de ese saber en las universidades que nos lleva al sistema anglosajón-, es en los años setenta cuando empieza a introducirse en las universidades. En el Estado español es ya en los años ochenta a través de los seminarios de estudios de la mujer en las universidades. Pero lo que quiero decir es 


\section{perifèria}

Número 13, diciembre 2010

www.periferia.name

que ya tenemos las herramientas teóricas y metodológicas. Y tenemos también un corpus de saber bien establecido a través de investigaciones serias, de tesis excelentes. Y también de toda una reflexión colectiva, de una reflexión que se hace a través de los cursos y los resultados de esos cursos, los trabajos que habéis ido haciendo, los libros que habéis leído... Todo eso está ahí. Y también contamos con otros referentes que me parece que son muy importantes, que son las leyes: la ley de violencia de género, las leyes de igualdad, tenemos ordenanzas municipales, planes de igualdad...

Todo eso codifica cierto saber, y a su vez lo tipifica en distintos momentos. Porque tú que sabes de violencia de género, puedes hablar de violencia sexista o puedes hablar de violencia sexual; y ya está tipificado. No sales desde cero sino que puedes recurrir a eso. Yo diría que están ya los mecanismos para poder ir haciendo ese análisis.

\section{P: Pero más específicamente, ¿qué dirías que han aportado y pueden aportar las perspectivas feministas en antropología?}

Teresa del Valle: Primero, a dar visibilidad a un saber, haciéndose a través del reconocimiento de las investigaciones. Y también del cuestionamiento que esas investigaciones hacen a la antropología. Precisamente en estos días vamos a tener un simposio en el que vamos a tratar un aspecto que tiene que ver con la relación entre parentesco y género ${ }^{3}$. Desde mi punto de vista, la antropología feminista enriquece a la antropología; es decir, crea preguntas que cuestionan el saber establecido. Porque hasta mediados de los setenta la mayor parte de las investigaciones que se hacían, aunque el género estaba presente como sistema de desigualdad en todas las sociedades (no solamente las estudiadas, sino en todas las sociedades con mayor o menor fuerza), éste no se trataba.

\footnotetext{
${ }^{3}$ Se refiere al simposio internacional "Procreación, crianza y género. Aproximaciones antropológicas a la parentalidad" que se celebró en la UAB (Barcelona), los días 13 y 14 de mayo, organizado por el Grup d'Estudi Transcultural del Parentiu (GETP) y el Grup de Recerca en Antropologia Fonamental i Orientada (GRAFO), del Departamento de Antropología Social y Cultural de dicha universidad.
} 


\section{perifèria}

Número 13, diciembre 2010

www.periferia.name

Verena Stolcke ha tratado lo que es la labor de las pioneras. Es muy interesante ver cómo esas mujeres empiezan ya en tiempos de Malinowski, en tiempos de Radcliffe-Brown, en tiempos de Lévi-Strauss, pero no se consideraba que su saber entrara en el eje de la disciplina. Creo que una de las aportaciones hechas es conceder a los ejes de la disciplina una visión que enriquece, haciendo que florezca lo que estaba a punto; que cuestiona silencios, que también cuestiona aportaciones que se han hecho, y que crea una tensión, una dialéctica entre el saber establecido y el que había ignorado. Porque tampoco los movimientos feministas habían entrado a impactar al mundo académico.

Segundo, entra en el eje de cuestiones que son básicas en el momento actual. Lo que es, por ejemplo, el tema de la violencia: de la violencia con las mujeres, la violencia con las niñas, etc. Entra de lleno en cómo nos hacen pensar en aspectos que tienen que ver con relaciones más igualitarias de las que teníamos. Por ejemplo, todo el tema de la corresponsabilidad de tareas que nos enriquece, (porque por lo demás, somos como mundos separados): lo que hacen los hombres, lo que hacemos las mujeres. Yo creo que la vida social es mucho más articulada de lo que muchas veces pensamos que es. Lo que nos ayuda a la integración social.

También nos revela distintos aspectos de la vida social que no "estaban": desde el punto de vista económico, desde el punto de vista simbólico,... Por ejemplo, todo el tema del ocultamiento de lo que las mujeres hemos ido haciendo como responsables de buena parte de la organización de lo doméstico y también del tejido de las relaciones familiares. Todo eso aparece, habiendo con ello también toda una aportación de cómo ha sido esa historia. Yo he trabajado sobre la usurpación de lo que yo llamo "los saberes culinarios de la cultura vasca". Ahora, vosotros estáis con Adrià; nosotros estamos ahí con toda la corte... Lo que es muy interesante son los procesos de conocimientos y de trabajos que se han dado; y el poco reconocimiento que han tenido porque dominaba el binarismo entre lo doméstico y lo público. En la medida en que se empieza a ver que la vida social es mucho más rica cuanto más articulada esté, van a aparecer también otras muchas formas de vida. Yo no las sé, pero tienen que ver con cómo están hombres y 


\section{perifèria}

Número 13, diciembre 2010

www.periferia.name

mujeres en esa articulación entre lo doméstico y lo público. Creo que va a beneficiar tanto a los hombres como a las mujeres, como a las sociedades donde se vayan dando. Una sociedad que supere los binarismos entre lo público y lo privado en concreto, creo que va a ser una sociedad más fluida y más participativa, aportando a lo social de una manera más vital. Podría seguir con todo el énfasis que en estos momentos se está dando a lo que tiene que ver con el mito del cuerpo, el derecho que las mujeres hemos esgrimido acerca de la decisión sobre nuestro cuerpo, que tenía que ver con caer en la cuenta de cómo estamos esclavizadas por los maltratos culturales, por las leyes acerca de decisiones que teníamos que hacer. Creo que esa es una forma también de adquirir libertad. Puedo mencionar bastantes contribuciones, unas que se han hecho, otras que se han iniciado, otras que están en el presente y otras que están en el futuro.

\section{P: En un estudio en el que ha participado dedicado a los nuevos modelos emergentes de los sistemas de relaciones de género, se propone "recoger críticamente las formas de ejercer el poder los varones $y$ discriminar en positivo aquellas estrategias que pueden ejercitarse de una manera intergenérica". Desde nuestra visión, toda discriminación supone una disgregación, una marginación. Nos preguntamos, ¿cómo partiendo de una discriminación se puede establecer una relación igualitaria?}

Teresa del Valle: Esto tiene que ver con el debate acerca de las cuotas: cuotas sí o cuotas no. Es un debate que aparece más liderado yo diría por los varones (el de cuotas no), pero también hay mujeres que se adscriben a ello. Yo estoy a favor de las cuotas, pero con una puntualización: partimos de un sistema de desigualdad tremenda. Sucede lo mismo con las lenguas minorizadas. Si las dejamos a su propia dinámica, nunca podrán estar en igualdad con las lenguas dominantes, esto también es así. Entonces, por ejemplo, el sistema de discriminación positiva me parece que es eficaz hasta que se llegue a una relación más equidistante. Recuerdo precisamente cuando fui a Estados Unidos, que me llamaba mucho la atención lo de la "discriminación positiva"; en aquellos momentos sucedía con las minorías. Recuerdo a la gente de la Universidad de Hawai donde yo estaba, desplazarse 


\section{perifèria}

Número 13, diciembre 2010

www.periferia.name

desde cualquier sitio de Estados Unidos porque pertenecía a la cuota de grupos minorizados. Eran afroamericanos, coreanos, asiáticos,... A mí me pareció una cosa muy normal, porque provenían de contextos socioeconómicos bastante precarios, donde nunca hubieran podido acceder a una formación universitaria o a estudiar fuera de su lugar. Luego se han ido viendo los frutos.

Lo que me habéis planteado como una dificultad yo no digo que sea discriminación "per se" y discriminación ya para siempre, sino que tiene que ver con esa desigualdad. Entonces, por ejemplo, pensando en los partidos políticos cuando vienen las elecciones: ¿cómo se hacen las listas? Por su propia inercia (no estoy metida en política pero por lo que he hablado con gente que sí lo está) es muy difícil que las mujeres entren en la lista de manera que vayan a salir elegidas. Entrar en el número veinte o veintiuno es facilísimo, pero no saldrán nunca.

Desde la experiencia que tengo, es como la pescadilla que se muerde la cola: las mujeres -y digo las mujeres porque ahora estamos hablando de esto, pero que podemos verlo en relación a otros grupos que están en una situación de desigualdad social- nunca podríamos entrar. $Y$ al no poder entrar tampoco tendríamos opción a ejercer. Y si no entras de manera que la posibilidad de ejercer sea a todos los niveles, nunca podríamos llegar a ello. Entonces, las "estrategias discriminatorias" van en ese sentido: son más bien, yo diría, como "estrategias de positivación".

A mí me pasa en experiencias muy concretas que he tenido en la presidencia del Congreso Internacional de la Sociedad de Estudios Vascos. Su comité científico tenía como criterio el que fuese paritario, y como consecuencia de eso ha sido así, puesto que éramos doce: seis y seis. Además, el comité científico tiene mucho que decir sobre la organización de un congreso, sobre la selección de ponentes. En la selección de ponentes establecimos también esa cláusula, siempre que se pudiera. Luego hubo algunos momentos que una ponente no podía venir, pues bueno; no creo que fuera totalmente paritario, pero casi paritario. Lo que quiero decir es que si no se entra en esos núcleos de influencia -a los niveles que sean, yo aquí he puesto un ejemplo, pero hay otros muchos- pues nunca se va a salir de ello. Hay 


\section{perifèria}

Número 13, diciembre 2010

$\underline{\text { www.periferia.name }}$

que crear estrategias, que se entendían en ese sentido: poner este tipo de normas para que pueda darse así. Pero claro, la norma no es discriminatoria, desde que tú acuerdas una norma o tienes la potestad de poder crear esa norma (lo mismo que si otra persona lo plantea con otros criterios, ¿no?). Pero yo creo que hay que estar y que hacen falta estrategias.

Otra cosa sobre las estrategias que también he comprobado: cuando estás en una situación en la que se cuecen muchas cosas (es decir, que hay encargos que se pueden dar a las personas que son muy importantes, hay investigaciones que se pueden dar, hay posibilidades de entrar en comités, etc.), se empieza a decir: dad nombres. Me he encontrado con que tenemos muchos menos nombres de mujeres que de hombres. A ver: no porque no existan mujeres igual de cualificadas, sino porque la inercia ha sido que los varones trabajaban más con las redes que se tejían con otros varones. Y claro, como también los varones han estado más en el poder existe ya una acumulación de referentes. Entonces puedes encontrarte con que tú quieres dar nombres de mujeres, pero en ese momento no tienes a mano los nombres. De esta forma una estrategia es que tú preparas nombres, nombres de mujeres que están bien cualificadas para ejercer ese trabajo y que en un momento dado pueden competir con los otros nombres que se den de varones. Esas son estrategias totalmente válidas a mí entender. Pero que requiere pensarlas, no surgen porque sí.

\section{P: Trasladándonos ahora al presente, en la actualidad trabaja en lo que usted da en denominar "espaciotemporalidades", y concretamente en el tema de la memoria. ¿Nos podría explicar brevemente qué líneas sigue su proyecto "La etnografía de la memoria"?}

Teresa del Valle: Bien. Difícil de resumir todo un libro. Hay una línea metodológica que está presente en él, que es una definición de lo que yo llamo "los ejes estructuradores del recuerdo". Que son cuatro: los hitos, las articulaciones, los intersticios y las encrucijadas. Son puntos de partida que parecen -a mí, por lo que yo voy viendo- que te llevan, de una manera puntual en unos casos, y en otros, de una manera que atraviesa la vida, a detectar ejes importantes. Aquí he prescindido 


\section{perifèria}

Número 13, diciembre 2010

www.periferia.name

de lo que he utilizado más habitualmente en otros contextos de investigación: las entrevistas en profundidad. Entonces yo lanzo para edificar el recuerdo ese tipo de puntos de partida. "¿Cuáles consideras tú en tu momento actual que han sido los momentos más importantes de tu vida?" Que serían los hitos, pero por las consecuencias que han tenido. Estos te llevan a repasar tu vida y a estructurarla de una manera que es la tuya, no la mía. Porque yo no le digo: "empieza por el hito de tu infancia"; la persona lo puede estructurar de la manera que quiera. Luego, yo voy cogiendo también aspectos que tienen que ver más con momentos de encrucijada, con momentos de decisión en los que se tenían distintas posibilidades de optar y se eligió una.

Otra sería los intersticios, que serían los momentos de clarividencia en los que se pensaba que se podía salir de una situación de encrucijada o de una situación difícil. Son momentos muy cualitativos, muchas veces ligados también a momentos emocionales. Y por último, quedarían las articulaciones, momentos de ajuste entre elementos que pueden aparecer como contrapuestos.

Este es un tipo de metodología que yo aprendí de Ira Progoff, que se basa en lo que se llama la "técnica del diario". Después se iría siguiendo de una manera cualitativa cada uno de esos elementos. Esto es algo que está presente en esta investigación.

Después he ido trabajando aspectos de la memoria que tienen que ver con distintos campos. Por ejemplo, hay una parte que ha sido la memoria del cuerpo, cómo el cuerpo recuerda. Lo que también está influenciado por esta metodología basada en Progoff. Cómo el cuerpo recuerda, y también la importancia de la memoria, que yo llamo la memoria encarnada, la memoria corporizada. Porque es la memoria pasada por la experiencia, o sea que ya no pertenece al recuerdo, sino a su intensificación. El caer en cuenta de cómo ese recuerdo se ha vivido, se ha corporizado, se ha asumido como parte de tu experiencia vital.

Hay otra dimensión que sería, por ejemplo, la relación entre memoria y espacio. Que también tiene que ver (o para mí ha tenido) con dar importancia al espacio a través de toda mi trayectoria como investigadora; y también ver cómo otras culturas leen el espacio. Trato de ver también distintas experiencias y distintas 


\section{perifèria}

Número 13, diciembre 2010

www.periferia.name

configuraciones de esa relación espacial a través de la memoria como fuente de conocimiento.

Está también la memoria del parentesco. Y luego, la relación entre memoria y arte. He seleccionado tres artistas diferentes. Una es Elena Asins, una escultura minimalista, con la que yo tengo un diálogo bastante continuo; ella desde el arte y yo desde la antropología. Después, una persona clave en mi trayectoria que es mi hermana Begoña, que era pintora, pintora espacialista y con la que siempre he mantenido un diálogo muy especial; también desde cómo ella concebía la memoria y el espacio. Y por último, referencias de algunos análisis que he hecho de la escultora Cristina Iglesias, la artífice de las puertas de la expansión del Museo del Prado en Madrid. Ella también trabaja mucho con el espacio, evidentemente, y con la memoria.

Bueno, esto serían algunas expresiones del enfoque que le estoy dando. En estos momentos estoy, espero, en la recta final de acabar el libro. Al menos me lo he propuesto ya para diciembre; a ver si puede ser.

P: Para terminar ya la última pregunta. Como usted dijo en la entrevista que le hizo Virginia Maqueira en el número especial de la revista Ankulegí4: "el arte encierra lo imprevisible del comportamiento humano, las posibilidades de generar nuevos contenidos, nuevos significados ante los avances de la técnica, o el surgimiento de problemas fruto de la destrucción y la decadencia". ¿Considera que estamos en decadencia?

Teresa del Valle: Algunos aspectos sí son muy decadentes en estos momentos. Yo diría, por ejemplo, todo el énfasis en las guerras. Eso para mí es totalmente decadente; aunque han sido siempre parte de la historia universal. Entonces depende de cómo una mire lo decadente. A mí me parece decadente, porque es precisamente ensalzar valores que tienen que ver con los enfrentamientos y que tienen que ver con las omnipresencias, las megalomanías y lo megapolítico. En este sentido, sí que estamos en una época decadente.

\footnotetext{
${ }^{4}$ Número especial de homenaje a Teresa del Valle de la revista de antropología Ankulegi, no12 (2008).
} 


\section{perifèria}

Número 13, diciembre 2010

www.periferia.name

También estamos en una época decadente desde el punto de vista de los Derechos Humanos. Desde que dejamos morir a la gente, dejamos la violencia de género salvaje, los feminicidios,... Todo ello es totalmente decadente. También el hambre.

Pero también estamos en una época de cambio. Pero yo no hablaría tanto, como algunos hablan, del fin de una era y el principio de la otra; yo creo que eso es como de ciencia ficción. Me parece que hay cambios importantes. En el mundo se habla de la globalización. Creo que sí, que hay cambios producto, no tanto de la globalización, sino de las dificultades para enfrentarnos a los extremos. Pues por un lado en este momento podemos comunicarnos con cualquier persona que tenga acceso a Internet. $Y$ al mismo tiempo puede haber una incomunicación total a niveles intergeneracionales, a niveles entre el profesorado y el alumnado, o entre las instituciones políticas y la ciudadanía. Entonces, me parece que es como esa sensación de que aparecen claros los problemas pero estamos siendo incapaces de salir al paso de esos problemas. Eso es lo que me parece. No sé qué otras cosas...

P: Bueno, a raíz de lo que acaba de responder, ¿qué cambios de los que se están produciendo considera más positivos o que tienen más futuro?

Teresa del Valle: El énfasis en los Derechos Humanos y la cantidad de gente implicada en ello. A mí me ha parecido muy importante todo el movimiento antiglobalización. Cuando se empezó a hablar tanto de la globalización, yo me sentía como oprimida y pensaba: "tiene que surgir algo, esto no es monolítico, tiene que haber fisuras". Siempre me parece importante prestar atención a las cosas que no aparecen como importantes. Y sobre todo a lo que pueden ser fisuras en lo que es un pensamiento o una práctica muy bien construida. Yo creo que hay que cuestionar. Cuando aparece todo tan bien construido, tan bien articulado, tan... ibuf! Algo pasa ahí.

De ahí que las fisuras sean importantes. De la aparición de los primeros movimientos antiglobalización, recuerdo el foro de Puerto Alegre, lo leí con verdadera codicia. Además, hay también toda una serie de mecanismos que se están poniendo en marcha de "formas distintas de hacer". Suelo prestar también mucha atención a movimientos como pueda ser un movimiento vecinal, que puede 


\section{perifèria}

Número 13, diciembre 2010

www.periferia.name

parecer una propuesta pequeña. Pero me parece que éstas son muy importantes.

Sí que creo que se han puesto en movimiento propuestas distintas y que algunas parece que son más positivas que otras. Por ejemplo, el hecho de que pueda haber una convocatoria a través de Internet, y la gente esté; que puedan recogerse cantidad de firmas, y la gente esté. En estos días, el que todo este tema vinculado a Garzón haya generado un mayor debate sobre la Ley de la Memoria Histórica. Y sobre el derecho que tenemos a reivindicar un pasado y a conocer ese pasado, antes de cerrarlo; hacerlo bien, hacer bien los cierres. Pues eso me ha parecido algo muy interesante.

Por ello yo creo que la Antropología tiene mucho que decir sobre las fisuras. Poder descubrir cosas que parecen pequeñas y si somos buenos antropólogos y buenas antropólogas, podemos hacerlo además de poder tener la capacidad de comunicarlo. Esto es algo a lo que nos podemos dedicar en estos momentos. Se nos ha atribuido la capacidad de comunicar información. Otra cosa será que comuniquemos bien la información. Pero nosotros sí que podemos generar buena información, porque trabajamos allí donde sucede eso, lo recogemos de las personas implicadas. Estudiamos los contextos y no nos importa, en principio, si estoy de acuerdo o si estoy en desacuerdo. Porque esa no es la tarea (el yo estar en acuerdo con lo que la gente me dice) sino el captar de la mejor manera posible los acuerdos y los desacuerdos de la gente.

Por eso yo creo que la Antropología tiene un campo muy importante en el análisis de las fisuras, en detectar las fisuras, estudiarlas y manifestarlas.

\section{P: Pues muchas gracias por todo.}




\section{perifèria}

Número 13, diciembre 2010

$\underline{\text { www.periferia.name }}$

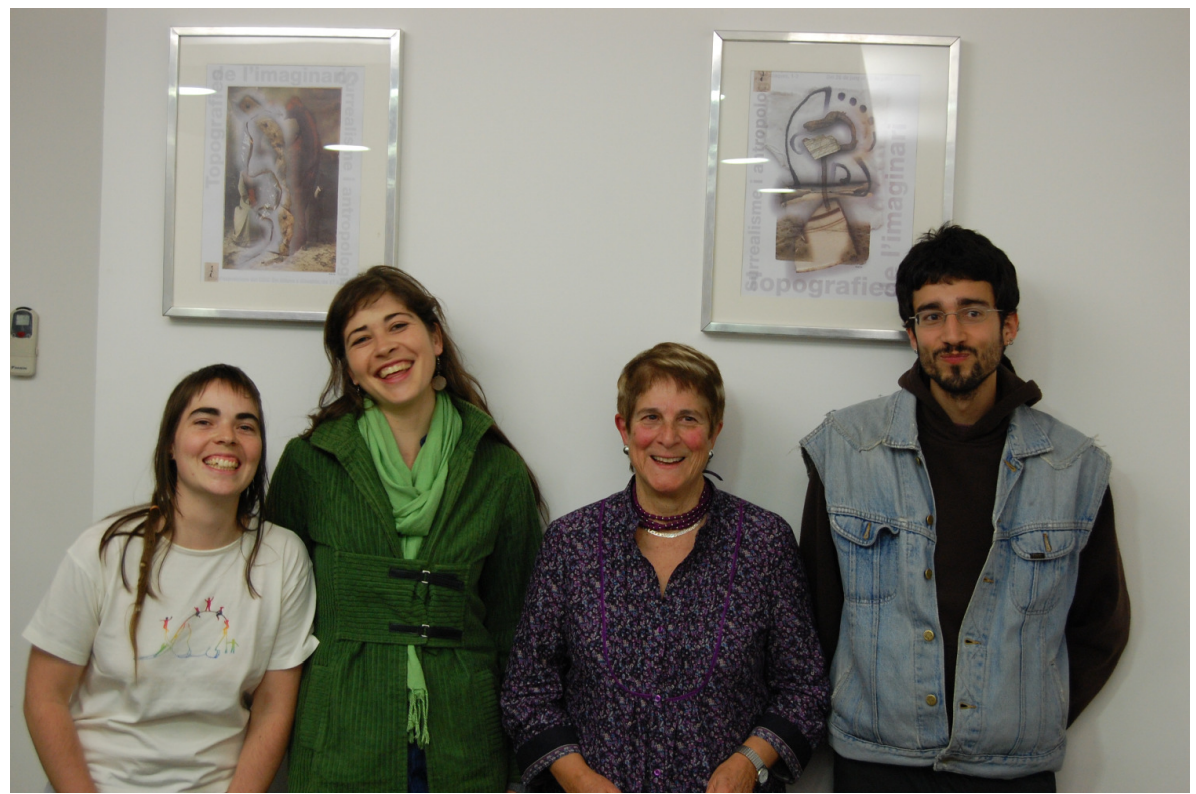

Sara Egido, Quesé Blanco, Teresa del Valle y Axel Aubinyà (fotografía Xavi Zulet) 